\title{
A FORMAÇÃO CONTINUADA DE PROFESSORES: ENTRE O REAL E O “IDEAL”"1
}

\author{
Fernanda Rossi \\ Universidade Estadual Paulista Júlio de Mesquita Filho, Bauru, São Paulo, Brasil \\ Dagmar Hunger \\ Universidade Estadual Paulista Júlio de Mesquita Filho, Bauru, São Paulo, Brasil
}

\begin{abstract}
Resumo
Objetivou-se evidenciar as perspectivas de um grupo de professores de Educação Física escolar, destacando os fatores apontados como imprescindíveis para uma formação continuada "ideal" para o aprimoramento profissional de um professor e para a sua ação pedagógica. De natureza qualitativa, a pesquisa inspirou-se no método de abordagem da história do tempo presente, visando registrar como memória o tempo em que vivem esses professores. Como fonte de dados, foram empregadas fontes orais, coletadas pela técnica de entrevista semiestrutura, e documentais oficiais. Os dados gerados foram discutidos com a produção da literatura e destacaram-se três eixos nos relatos dos docentes: a relação entre a teoria e a prática, a importância de ouvir os alunos e a continuidade das ações formativas.

Palavras-chave: Formação Continuada de Professores. Desenvolvimento Profissional. Educação Física.
\end{abstract}

\section{Introdução}

o pensar os processos de ensino e aprendizagem no contexto
atual, um tema torna-se recorrente: a formação continuada de professores. Atribui-se ao docente a responsabilidade pela aprendizagem do alunado e deposita-se toda confiança nesse agente para a transformação da educação brasileira, mediante investimento na sua formação permanentemente.

A formação continuada de professores vem recebendo destacada atenção no campo educacional, notadamente a partir da década de 1990, devido, especialmente, às pressões do mundo do trabalho e à constatação dos precários desempenhos escolares de grandes parcelas da população pelos sistemas governamentais. Com isso, a formação

1-Apoio: CNPq.

Pensar a Prática, Goiânia, v. 15, n. 4, p. 821-1113, out./dez. 2012 
contínua passou a integrar a maioria das reformas educativas (GATTI, 2008).

No entanto, em muitas práticas formativas não se nota a preocupação, por parte do poder público e de outros atores responsáveis pelas ações de formação, em considerar o professor como um sujeito ativo de seu próprio desenvolvimento e suas experiências adquiridas no exercício da profissão docente, estabelecendo os saberes experienciais (TARDIF, 2002) como o foco da ação. Como consequência, o cenário da formação continuada evidencia que muitas ações não têm contribuído efetivamente para gerar mudanças na prática pedagógica (ROSSI e HUNGER, 2010).

Com o objetivo de ouvir o que tem a dizer o professorado sobre suas experiências, nesta pesquisa discutimos as perspectivas de um grupo de professores de Educação Física escolar, evidenciando os fatores que destacaram como imprescindíveis para uma formação continuada considerada "ideal" para o aprimoramento profissional de um professor e para a sua ação pedagógica. Do mesmo modo, destacamos os contextos em que vivem os docentes no seu cotidiano, buscando estabelecer diálogo entre a realidade desse grupo e o que esperam em termos de formação. Buscou-se investigar a problemática da formação continuada, apresentada na atualidade, com inspiração no método de abordagem da história do tempo presente, empregando fontes orais, coletadas pela técnica de entrevista semiestrutura, e documentais oficiais, discutindo-os com a produção da literatura.

Partimos da análise dos documentos oficiais, delineando a formação continuada no cenário brasileiro, tendo como fonte de dados a Lei de Diretrizes e Bases da Educação Nacional n. 9.394/96 (BRASIL, 1996), os Referenciais para Formação de Professores (BRASIL, 2002), o Programa de Desenvolvimento Profissional Continuado Parâmetros em Ação (BRASIL, 1999), a Rede Nacional de Formação Continuada de Professores (BRASIL, 2004), a Lei n. 11.502 (BRASIL, 2007), que originou a chamada Nova Capes e as Diretrizes Curriculares Nacionais Gerais para a Educação Básica - Parecer CNE/CEB 7/2010 (BRASIL, 2010a) e Resolução CNE/CEB 4/2010 (BRASIL, 2010b). E, na sequência, são discutidos os relatos dos professores nos eixos: a relação entre a teoria e a prática, a importância em ouvir os alunos e a continuidade das ações formativas. 


\section{Diretrizes nacionais para a formação continuada de professores: panorama do cenário brasileiro}

A promulgação da Lei de Diretrizes e Bases da Educação Nacional, a LDBEN 9.394, em 1996 (BRASIL, 1996), impulsionou as ações políticas de formação continuada de professores. Como ressalta Gatti (2008, p. 64), a nova LDB "veio provocar especialmente os poderes públicos quanto a essa formação. A lei reflete um período de debates sobre a questão da importância da formação continuada e trata dela em vários de seus artigos". Assim, expandiu-se de forma exponencial a oferta de programas ou cursos de educação continuada a partir desse período.

A formação docente (inicial e continuada) é tratada na LDBEN no Título VI - Dos profissionais da educação. O $\S 1^{\circ}$ do artigo 62 (incluído em 2009 pela Lei n. 12.056/09) versa sobre o papel da União, Distrito Federal, Estados e Municípios que, em regime de colaboração, deverão promover a formação inicial, a continuada e a capacitação dos profissionais de magistério. Enquanto que o artigo 63, inciso III, define que os Institutos Superiores de Educação deverão manter programas de educação continuada para os profissionais da educação dos diversos níveis. Já o artigo 67 traz que os sistemas de ensino deverão promover a valorização dos profissionais da educação por meio do aperfeiçoamento profissional continuado, e propõe, inclusive, o licenciamento periódico remunerado para esse fim (inciso II).

Posteriormente à promulgação da LDBEN, foram elaboradas diretrizes com o objetivo de subsidiarem o desenvolvimento de ações de formação continuada nas secretarias estaduais e municipais de educação. De modo geral, as instâncias políticas justificam a formação continuada nos documentos pela necessidade de atualização dos professores frente aos novos desafios educacionais e às discussões teóricas recentes, visando propiciar mudanças na ação pedagógica e na qualidade da educação brasileira, de tal forma que essa dimensão da formação vai ganhando espaço nos documentos oficiais.

O MEC apresentou os Referenciais para Formação de Professores (BRASIL, 2002), que teve sua primeira versão tornada pública no ano de 1997. No documento, constata a necessidade de investimento na formação dos professores como uma medida emergente na busca da superação do fracasso dos alunos. Embora constate que o professor não é o único ou o principal responsável pelo insucesso escolar, indica 
que ele é "imprescindível para a superação de parte dos problemas educativos" (BRASIL, 2002, p. 33).

Compreende que "a formação de professores é um requisito fundamental para as transformações que se fazem necessárias na educação" (BRASIL, 2002, p. 34), bem como para a atualização constante diante das rápidas mudanças da sociedade. Assim sendo, além da formação inicial, a formação continuada é uma necessidade intrínseca na área educacional e deve fazer parte de um processo permanente de desenvolvimento profissional, assegurado a todos os profissionais da educação.

Ao tratar das políticas de formação no que cabe às secretarias de educação, o documento aponta algumas das responsabilidades que essas instâncias devem assumir, enfatizando "a criação de condições para que a formação continuada possa ocorrer dentro da jornada regular de trabalho dos profissionais da educação, sem prejuízo das horas de docência" (BRASIL, 2002, p. 135-136).

Com o intuito de auxiliar a implementação dos PCNs, o MEC propôs o programa de desenvolvimento profissional continuado por meio do projeto Parâmetros em Ação (BRASIL, 1999). Desenvolvido em parceria com as secretarias estaduais e municipais, visa propiciar a aprendizagem coletiva na escola e o aprofundamento dos estudos referentes aos PCNs, de modo que novas possibilidades de trabalho sejam criadas para melhorar a qualidade da aprendizagem dos alunos.

A criação de mais um programa se deu no ano de 2004, quando foi instituída pelo MEC a Rede Nacional de Formação Continuada de Professores (BRASIL, 2004). A rede é formada por instituições de ensino superior (IES) públicas, federais e estaduais, e comunitárias, sem fins lucrativos, constituindo Centros de Pesquisa e Desenvolvimento da Educação. Em parceria com outras instituições de ensino, esses centros produzem materiais instrucionais e de orientação para cursos a distância e semipresenciais, formando uma rede de atuação para atender às necessidades e às demandas dos sistemas de ensino (estaduais e municipais).

O MEC define os seguintes princípios para a Rede: a formação continuada é exigência da atividade profissional no mundo atual; deve ter como referência a prática docente e o conhecimento teórico; vai além da oferta de cursos de atualização ou treinamento; para ser continuada deve integrar-se no dia a dia da escola; é componente essencial da profissionalização docente. 
De acordo com o MEC, o suporte técnico e financeiro para as atividades da rede é oferecido pelo Ministério, além de coordenar o desenvolvimento do programa, que Estados, Municípios e Distrito Federal implementam por adesão, em regime de colaboração (BRASIL, 2004).

Observa-se, nos últimos anos, uma nova configuração em termos normativos sendo delineada para a formação de professores no Brasil. O governo federal transformou, em 2007, a Coordenação de Aperfeiçoamento de Pessoal de Nível Superior (Capes) em agência reguladora da formação de professores, em suas diferentes etapas - inicial e continuada - criando a chamada Nova Capes. De acordo com a Lei n. 11.502 (BRASIL, 2007), agora, além de subsidiar o MEC nas políticas de pós-graduação,

§ 2o No âmbito da educação básica, a Capes terá como finalidade induzir e fomentar, inclusive em regime de colaboração com os Estados, os Municípios e o Distrito Federal e exclusivamente mediante convênios com instituições de ensino superior públicas ou privadas, a formação inicial e continuada de profissionais de magistério, respeitada a liberdade acadêmica das instituições conveniadas.

Com a criação da Nova Capes, o MEC incorpora a Universidade Aberta do Brasil (UAB), definindo, ainda no parágrafo $2^{\circ}$, que "II - na formação continuada de profissionais do magistério, utilizar-se-ão, especialmente, recursos e tecnologias de educação a distância". (BRASIL, 2007).

Mais recentemente, em 2010, foram estabelecidas as Diretrizes Curriculares Nacionais Gerais para a Educação Básica, por intermédio do Parecer CNE/CEB 7/2010 (BRASIL, 2010a) e da Resolução CNE/CEB 4/2010 (BRASIL, 2010b). As diretrizes têm por objetivo, entre outros,

III - orientar os cursos de formação inicial e continuada de docentes e demais profissionais da Educação Básica, os sistemas educativos dos diferentes entes federados e as escolas que os integram, indistintamente da rede a que pertençam (BRASIL, 2010b). 
O capítulo IV, "O professor e a formação inicial e continuada", do título VII, "Elementos constitutivos para a organização das diretrizes curriculares nacionais gerais para a educação básica", é dedicado à formação docente. $\mathrm{O}$ artigo $56, \S 1^{\circ}$, prevê que as escolas de formação (inicial e continuada) dos profissionais da educação, sejam gestores, professores ou especialistas, deverão incluir em seus currículos e programas o conhecimento da escola como organização complexa, cuja função consiste na promoção da educação para e na cidadania; a pesquisa, a análise e a aplicação dos resultados de investigações; a participação na gestão de processos educativos e na organização e funcionamento de sistemas e instituições de ensino; a gestão democrática, enfatizando a construção do projeto político-pedagógico pelo trabalho coletivo e como responsabilidade de todos os que compõem a comunidade escolar.

Os programas de formação inicial e continuada devem preparar os profissionais da educação, de acordo com o artigo $57 \S 2^{\circ}$, para:

a) além de um conjunto de habilidades cognitivas, saber pesquisar, orientar, avaliar e elaborar propostas, isto é, interpretar e reconstruir o conhecimento coletivamente;

b) trabalhar cooperativamente em equipe;

c) compreender, interpretar e aplicar a linguagem e os instrumentos produzidos ao longo da evolução tecnológica, econômica e organizativa;

d) desenvolver competências para integração com a comunidade e para relacionamento com as famílias. (BRASIL, 2010b).

O artigo 58 reforça que a formação inicial não esgota o desenvolvimento dos conhecimentos, saberes e habilidades referidas. Portanto, devem ser contemplados programas de formação continuada no projeto político-pedagógico (BRASIL, 2010b).

Diante de tais apontamentos nos documentos oficias, questionamos: Os registros apresentados nas diretrizes correspondem à realidade dos professores no seu cotidiano? Atendem às suas necessidades profissionais? Como estão delineadas as práticas de formação continuada na realidade docente e o que pensam os professores com relação ao que seria uma prática formativa eficiente, ou seja, quais seriam os delineamentos de uma formação continuada considerada "ideal" sem suas concepções? 


\section{Delineamentos metodológicos}

Para responder às questões propostas, optamos pela abordagem qualitativa que, de acordo com André (1995, p. 17), baseia-se em princípios como a valorização da "maneira própria de entendimento da realidade pelo indivíduo", não aceitando que a realidade seja algo externo ao sujeito. É essencial a visão holística dos fenômenos, considerando-se que fatos e valores estão intimamente relacionados.

Essa foi a abordagem adequada ao objetivo da pesquisa, uma vez que se trata da compreensão da percepção de mundo e das opiniões subjetivas que os indivíduos associam aos fenômenos de sua vida - os professores. Nesse sentido, pontua André (1995, p. 17) que, para Weber, "o foco da investigação deve se centrar na compreensão dos significados atribuídos pelos sujeitos às suas ações. Como Dilthey, ele argumenta que para compreender esses significados é necessário colocá-los dentro de um contexto". O contexto, nesta pesquisa, refere-se ao desenvolvimento profissional docente e às relações que necessitam ser estabelecidas para a construção de novos olhares sobre sua formação continuada.

Diante dessa concepção, buscamos investigar a problemática da formação continuada com inspiração no método de abordagem da história do tempo presente, deixando registrado como memória aspectos do momento atual da educação brasileira (AMADO; FERREIRA, 1996).

Como técnicas de pesquisa, empregamos fontes documentais e fontes orais, gerando os relatos pela técnica de entrevista semiestruturada. Os dados foram analisados em diálogo com a produção da literatura. Os entrevistados foram professores de Educação Física, atuantes na educação básica da rede pública de ensino do interior do estado de São Paulo. Os conjuntos de dados gerados por esse grupo representativo revelaram alguns eixos para as análises, como: a relação entre a teoria e a prática, a importância de ouvir os alunos e a continuidade das ações formativas.

\section{Formação continuada de professores: entre o real e o "ideal" na pers- pectiva docente}

Buscamos dar ênfase às concepções dos professores, ouvir o que têm a dizer os sujeitos principais do processo de formação continuada, 
com o intuito de contribuir para o (re)pensar da formação docente, mediante a reconfiguração dos modelos formativos.

Os depoimentos dos professores revelaram, a partir de suas concepções, o que seria uma formação continuada "ideal", que pudesse auxiliar na produção de práticas pedagógicas diferenciadas. Lembramos que professores em diferentes fases da carreira docente podem manifestar expectativas e dificuldades diversas, de acordo com o momento que estão vivendo e o contexto em que estão inseridos (HUBERMAN, 2000). De todo modo, as falas dos depoimentos são elucidativas das necessidades emergentes no que se refere à sua formação profissional.

A discussão teoria x prática

Ao abordar a temática da formação continuada, os professores destacaram a relação entre a teoria e a prática, questão constantemente polêmica nos debates sobre a formação docente. Como lembra Chakur (2000, p. 79), a formação inicial nas licenciaturas é baseada em dicotomias como: "teoria x prática, ensino $\mathrm{x}$ pesquisa, qualidade $\mathrm{x}$ quantidade, especialidade $\mathrm{x}$ generalidade, licenciatura $\mathrm{x}$ bacharelado, 'formação específica' x 'formação pedagógica'”.

Por vezes, tais dualidades também estão presentes na formação continuada. É o que revela o relato de uma das professoras. Indicação dos caminhos a seguir e superação da formação demasiada teórica, que desconsidera as dificuldades dos docentes, são as reivindicações de mudança feitas pela docente, para uma prática de formação que considera "ideal":

A gente falaria as nossas dificuldades e as pessoas... não é, não quero receita pronta, eu queria só caminhos, caminhos pra gente seguir e eu sei que em livros também tem caminhos, não receitas, mas tem caminhos. Mas, assim, que seja trabalhado menos a parte teórica e mais a parte prática. Para nossas dificuldades, eu acho que a gente conseguiria um resultado um pouquinho mais efetivo do que só teoria, teoria, teoria.

Charlot (2000) critica a tentativa de classificar os saberes em espécies: prático, teórico, científico, profissional, etc. $\mathrm{O}$ saber não é um objeto, não é ele que é prático em si mesmo, mas se torna prático ou 
teórico somente no seu uso na relação com o mundo. Em outras palavras, a relação com o saber pode ser prática, mas não o saber em si mesmo, já que depende sempre da relação que o sujeito estabelece com ele.

A teoria do autor parece ampliar a ideia das dimensões dos conteúdos (conceitual, procedimental e atitudinal) porque aborda as diferentes formas de aprender e a natureza dos saberes e dos conhecimentos por meio de uma relação - uma relação que é estabelecida entre o sujeito e o mundo - de forma mais interdependente e articulada. Essa possibilidade de compreensão pode caminhar na tentativa de romper com preconceitos ligados ao universo dos saberes, atividades, conhecimentos que não são de natureza intelectual (aqueles que o autor caracteriza como saberes-objetos), assim como diluir as dicotomias prático $\mathrm{x}$ teórico; concreto $\mathrm{x}$ abstrato, etc. (CHARLOT, 2000).

Todas as nossas ações exigem certos saberes e reflexão crítica sobre nossas práticas, como nos explica Paulo Freire (1996, p. 22):

A prática de velejar coloca a necessidade de saberes fundantes como o do domínio do barco, das partes que o compõem e da função de cada uma delas, como o conhecimento dos ventos, de sua força, de sua direção, os ventos e as velas, a posição das velas, o papel do motor e da combinação entre motor e velas. $\mathrm{Na}$ prática de velejar se confirmam, se modificam ou se ampliam esses saberes.

O ato de ensinar supõe saberes concernentes à educação, à sociedade, à história, ao conhecimento, aos sujeitos. Supõe conhecer a educação na sua integridade. É o que concebe um dos depoentes que também abordou a questão da teoria/prática em seus relatos, apontando o respaldo teórico como um dos aspectos imprescindíveis para a construção de ações formativas críticas, sendo necessária a relação universidade-escola para essa realização.

Não obstante, o processo de formação continuada tem de considerar que o professor em formação não é um aluno como aquele da formação inicial; traz consigo suas vivências, ideologias, toda uma experiência em aula, enfim, uma condição docente permeada de historicidade do seu fazer didático-pedagógico.

Ainda parafraseando Paulo Freire, 
na formação permanente dos professores, o momento fundamental é o da reflexão crítica sobre a prática. É pensando criticamente a prática de hoje ou de ontem que se pode melhorar a próxima prática. $\mathrm{O}$ próprio discurso teórico, necessário à reflexão crítica, tem de ser de tal modo concreto que quase se confunda com a prática. (FREIRE, 1996, p. 39)

Enfim, na compreensão de Betti (2005, s/p.),

[a] teoria adquire um sentido de unidade com a prática, não no sentido estático de dar explicações às questões práticas, mas no sentido dinâmico de auxiliar o encaminhamento, a direção refletida, crítica e criativa da situação. A teoria é vista como reveladora de várias alternativas e, pela análise e diálogo com a situação, contribui para fazer avançar o conhecimento sobre a validade de cada uma delas, e assim são geradas relações de interrogações mútuas entre a teoria e a prática, em decorrência do que ambas se transformam.

A importância em ouvir os alunos para o (re)pensar da formação docente

Ainda não temos um número considerável de pesquisas no campo educacional que enfoquem o aluno como sujeito principal do processo investigativo, concebendo-o como um indivíduo situado historicamente, numa determinada configuração sociocultural. Os discursos apontam para sua centralidade, entretanto são poucas as pesquisas que investigam esse sujeito a partir do que eles têm a dizer. Nesse sentido, apontam os professores entrevistados para a relevância de compreender as necessidades e perspectivas dos alunos com relação à escola e ao processo educacional, inclusive ao tratar da formação do docente, pois acreditam que é preciso "levar muito em conta também [...] a voz dos alunos, o que eles estão percebendo".

Como dizia Paulo Freire (1996, p. 23), ensinar exige respeito aos saberes dos educandos, sobretudo os saberes socialmente construídos na vida comunitária, aproximando o ensino da vida concreta, visando a transformação social. Afinal, "não há docência sem discência".

Goedert (2005, p. 7) ressalta que um dos maiores desafios para a área da Educação Física consiste em construir um ensino no qual a 
cultura jovem possa participar como elemento efetivo da cultura escolar. Acredita que "a cultura jovem, ao participar na construção das práticas escolares da educação física poderá levar para o interior destas valores, crenças, sentidos e significados".

A valorização do que pensam os alunos é relevante pelo fato de estes participarem da construção do cotidiano da escola e para compreendermos como se relacionam com os diferentes saberes que circulam no ambiente escolar.

Desde que nascemos somos obrigados a aprender, a nos apropriarmos do mundo, como salienta Charlot (2000). E são muitas as maneiras pelas quais apreendemos o que está ao nosso redor, sendo que o sentido atribuído às nossas experiências é elemento-chave para nos relacionarmos com os outros, com o meio em que vivemos. Logo, é imprescindível considerar o sujeito ao estudar o campo da educação.

O sociólogo aborda a relação com o saber como resultado de diferentes lógicas para sua apreensão, sendo necessário compreender, primordialmente qual é o processo que leva o aluno a adotar uma relação de saber com o mundo. Nesse sentido, apresenta como pressuposto que toda relação com o saber é uma relação de sentido e significado, que depende da relação de um sujeito com o mundo, com o outro e consigo mesmo, ou seja, é um efeito da interação sujeito-mundo. Tal relação envolve questões como: a mobilização intelectual para a aprendizagem, dispor-se a aprender; de sentido e de prazer, que envolve despertar no aluno o desejo pelo saber. Enfim, é preciso que o professor/escola encontre meios para estimular o aluno a mobilizar-se a aprender, encontrar sentido e prazer nas atividades escolares.

Para tanto, tem-se de considerar as múltiplas faces do processo de ensino-aprendizagem, como as razões, atitudes e comportamentos discentes nas diferentes relações: epistêmicas (com conhecimentos, conteúdos, atividades, diferentes linguagens...); identitárias (com o professor, com os alunos, com a escola, consigo mesmo) e sociais (com a escola, com o coletivo). O conhecimento do alunado também é condição para pensar as ações de formação docente.

\section{A necessária continuidade das ações formativas}

Não basta implementar ações formativas de diferentes naturezas, em espaços e com conteúdos diversificados, ressaltaram os professo- 
res. As ações precisam ser contínuas e não configurar-se somente como atividades pontuais:

Deveria existir alguma coisa assim no sentido de acompanhar esse professor, alguma coisa que não fosse pontual, entendeu? Então, uma discussão, um evento, um... que é o que a gente observa, assim. É uma coisa que não é contínua, então ela é interrompida. Você vai, discute alguma coisa, fica lá quatro horas discutindo e depois dali seis meses você vai fazer aquilo novamente, entendeu? Então, poderia existir alguma forma, não sei como isso seria colocado em prática, mas alguma forma de que o professor sempre estivesse em formação, sempre estivesse discutindo.

Ao passo que, para um dos entrevistados, a preparação do professor teria que começar antes do início do ano letivo (abordando a dimensão psicológica e os conhecimentos específicos) e ser dada continuidade durante todo o ano, assim como essa formação seria imprescindível antes de toda mudança a ser introduzida na escola:

Deveria ter um, um tempo, é... antes de começar o ano letivo, uma preparação do professor, tanto psicológica como com cursos. [...] Toda mudança tem que ter uma preparação, entendeu? Toda mudança que está sendo feita é jogada, não preparada. Eu acho que deveria preparar mais o professor. Continuada é o quê? No começo do ano, no meio do ano, no final do ano [...].

Para Maués (2003), não há políticas educacionais amplas de formação de professores, o que se tem na verdade são planos pontuais e de acordo com interesses momentâneos, tanto políticos quanto econômicos. Enfatiza Ferreira (2003) que a política de formação continuada tem se tornado, de fato, uma política de descontinuidade, caracterizada pelo constante recomeçar, desconsiderando aquilo que já foi produzido pela história.

Lembra Chauí (2003, p. 11) que "educação significa um movimento de transformação interna daquele que passa de um suposto saber (ou da ignorância) ao saber propriamente dito (ou à compreensão de si, dos outros, da realidade, da cultura acumulada e da cultura no seu presente ou se fazendo)". Concordamos com a autora que "a edu- 
cação é inseparável da formação e é por isso que ela só pode ser permanente". Assim como mencionou uma entrevistada, tem que ser "ao longo da vida, a gente nunca pode parar. [...] porque a gente nunca sabe tudo, a gente vai aprendendo [...]. Então, é um espaço para o aprimoramento".

\section{Considerações finais}

A partir da discussão dos relatos desse grupo de professores, constatamos que a formação continuada deve ter suas bases nas vivências dos professores no cotidiano escolar, valorizando os saberes da experiência, sem, contudo, desvalorizar a importância das construções teóricas. A questão está em articular dialeticamente as duas dimensões. Como bem diz Paulo Freire (1996, p. 22), "a reflexão crítica sobre a prática se torna uma exigência da relação Teoria/Prática sem a qual a teoria pode ir virando blablablá e a prática, ativismo". Ressaltou-se, também, a importância em considerar as concepções dos alunos em todo o processo docente, inclusive na formação dos professores.

Para o grupo de entrevistados, emerge pensar na formação continuada como um processo efetivamente contínuo, superando atividades pontuais. A continuidade das ações é elemento fundador para a evolução da profissionalidade docente e prática pedagógica. Como nos diz Marcelo García $(1995,1999)$, as distintas fases por que passa o professor no processo de aprender a ensinar delineiam-se como formação inicial, período de iniciação e desenvolvimento profissional. A noção de desenvolvimento profissional traz consigo a ideia de evolução e de continuidade (superando a justaposição entre formação inicial e aperfeiçoamento dos professores), assim como pressupõe a valorização dos aspectos contextuais, organizacionais e orientados para a mudança, numa tentativa de superação do caráter individualista nas atividades de formação continuada, colocando a ênfase na dimensão participativa (ativa) dos professores.

Desse modo, considerando as necessidades expressas pelos depoentes da presente pesquisa, espera-se para as práticas de formação docente no futuro: a superação da concepção em que o sujeito a se formar, o professor-aluno, se encontre na posição de passividade, receptor de conteúdos elaborados por outros. Que as políticas de formação sejam processos compartilhados entre professores, gestores, formadores, acadêmicos e não elaboradas unilateralmente. Que o pró- 
prio professor estabeleça os desafios e reconheça as experiências vividas que possam influenciar as mudanças educativas. Que a prática docente se torne a referência principal dos programas de formação continuada - assim como está registrado nas propostas oficiais nacionais, mas que não acontece no cotidiano. Que as concepções dos alunos também sejam consideradas para o (re)pensar da formação docente. Que a formação continuada não seja desvinculada da formação inicial ou do processo de indução à carreira, prestando atenção ao conceito de desenvolvimento profissional. Que o ponto de partida de conscientização do professorado para a adoção de uma postura de desenvolvimento profissional permanente integre o percurso da formação inicial. Que diferentes práticas de formação sejam valorizadas como, por exemplo, a cultural e a artística, e não somente a acadêmico-científica, pois a formação do professorado não acontece apenas quando há certificação ou uma formação institucionalizada, uma vez que professor (vida profissional) e pessoa (vida pessoal) não se separam (NÓVOA, 1995, 2000), tratando-se, portanto, de formação humana.

Por conseguinte, que a formação não seja um componente isolado da profissão docente e que se traduza em oportunidades para que o professor transcenda a posição de profissional técnico que implementa prescrições de outros, convertendo-se em um profissional que participe ativa e criticamente no processo de inovação e mudança educacional e social. Correspondendo, assim, ao que está previsto nos documentos oficiais, como na Resolução CNE/CEB 4/2010 (art. 59, BRASIL, 2010b), que propõe que os sistemas educativos devem instituir orientações para que o projeto de formação dos profissionais preveja a consolidação da identidade dos profissionais da educação, o resgate da imagem social do professor e da autonomia docente (individual e coletiva) e, ainda, que as agências formadoras de profissionais da educação reavaliem seus projetos de formação inicial e continuada, para corresponder a um projeto de nação.

\title{
Continuing education teacher: between the real and the "ideal"
}

\begin{abstract}
The objective this study was to highlight the prospects of a group of teachers of Physical Education, highlighting the factors identified as critical to a continuing education "ideal" for a teacher professional development and for the practice pedagogical. Qualitative research, inspired by the method of approaching the history
\end{abstract}


of the present time, in order to register as memory the time when these teachers live. The data source used was oral sources collected by the technique of semistructured interviews and official documents. The data generated were discussed with the production of literature and the highlights are three axes in the reports of teachers: the relationship between theory and practice, the importance of listening to students and the continuity of training activities.

Keywords: Continuing Education. Professional Development. Physical Education.

\section{Educación continuada docente: entre lo real y el "ideal"}

\section{Resumen}

El objetivo era evidencia las perspectivas de un grupo de profesores de Educación Física, destacando los factores identificados como críticos para una educación continua "ideal" para un desarrollo profesional docente y para práctica pedagógica. La investigación cualitativa, inspirada en el método de acercarse a la historia del tiempo presente, con el fin de registrarse como un recuerdo del momento en que estos maestros en vivo. La fuente de datos utilizada fuentes orales recogidas por la técnica de entrevistas semi-estructuradas y documentos oficiales. Los datos generados se discutieron con la producción de la literatura y los aspectos más destacados son los tres ejes en los informes de los profesores: la relación entre la teoría y la práctica, la importancia de escuchar a los estudiantes y la continuidad de las actividades de formación.

Palabras clave:Educación Continua. Desarrollo Profesional. Educación Física.

\section{Referências}

AMADO, J.; FERREIRA, M. M. (Orgs.). Usos \& abusos da história oral. Rio de Janeiro: Fundação Getúlio Vargas, 1996.

ANDRÉ, M. E. D. A. Etnografia da prática escolar. Campinas: Papirus, 1995.

BETTI, M. Sobre teoria e prática: manifesto pela redescoberta da educação física. Lecturas: Educación Física y Deportes (Revista Digital), Buenos Aires, ano 10, n. 91, dez. 2005. Disponível em: $<$ http://www.efdeportes.com/efd91/ef.htm>. Acesso em: 03 jun. 2011.

BRASIL. Congresso Nacional. Lei n. 9.394, de 20 de dezembro de 1996. Estabelece as diretrizes e bases da educação nacional. Diário Oficial da União, Brasília, DF, 23 dez. 1996.

. Ministério da Educação. Secretaria de Educação Fundamental. Programa de Desenvolvimento Profissional Continuado. 
Parâmetros em Ação, Terceiro e Quarto Ciclos do Ensino Fundamental. Brasília: MEC/SEF, 1999.

- Ministério da Educação. Secretaria de Educação Fundamental. Referenciais para Formação de Professores. Brasília: MEC/SEF, 2002.

- Ministério da Educação. Secretaria de Educação Básica. Rede Nacional de Formação Continuada de Professores. Brasília: MEC, 2004. Disponível em: <http://www.mec.gov.br>. Acesso em: 31 jul. 2009.

. Congresso Nacional. Lei n. 11.502, de 11 de julho de 2007. Modifica as competências e a estrutura organizacional da fundação Coordenação de Aperfeiçoamento de Pessoal de Nível Superior - Capes. Diário Oficial da União, Brasília, DF, n. 133, 12 jul. 2007.

. Conselho Nacional de Educação, Câmara de Educação Básica. Parecer n. 7, de 4 de abril de 2010. Diretrizes Curriculares Nacionais Gerais para a Educação Básica. Diário Oficial da União, Brasília, DF, 9 jul. 2010a.

. Conselho Nacional de Educação, Câmara de Educação Básica. Resolução n. 4, de 13 de julho de 2010. Define Diretrizes Curriculares Nacionais Gerais para a Educação Básica. Diário Oficial da União, Brasília, DF, 14 jul. 2010b.

CHAKUR, C. R. de S. L. (Des)profissionalização docente e formação continuada: situação e perspectivas atuais. In: LEITE, C. D. P.; OLIVEIRA, M. B. L. de; SALLES, L. M. F. (Orgs.). Educação, psicologia e contemporaneidade. Taubaté: Cabral Editora Universitária, 2000. p. 71-89.

CHARLOT, B. Da relação com o saber: elementos para uma teoria. Porto Alegre: Artmed, 2000.

CHAUÍ, M. A universidade pública sob nova perspectiva. Revista Brasileira de Educação, Rio de Janeiro, n. 24, p. 5-15, set.-dez. 2003.

FERREIRA, N. S. C. Formação continuada e gestão da educação no contexto da "cultura globalizada". In: FERREIRA, N. S. C. (Org.). 
Formação continuada e gestão da educação. São Paulo: Cortez, 2003.

FREIRE, P. Pedagogia da autonomia: saberes necessários à prática educativa. 33. ed. São Paulo: Paz e Terra, 1996.

GATTI, B. A. Análise das políticas públicas para formação continuada no Brasil, na última década. Revista Brasileira de Educação, [S.1.], v. 13, n. 37 , p. 57-70, jan.-abr. 2008.

GOEDERT, R. T. A cultura jovem e as suas relações com a educação física escolar. 2005. 2 v. 156 p. Tese (Doutorado em Educação). Universidade Federal do Paraná, Curitiba, 2005.

MARCELO GARCÍA, C. A formação de professores: novas perspectivas baseadas na investigação sobre o pensamento do professor. In: NÓVOA, A. (Org.). Os professores e a sua formação. Lisboa: Dom Quixote, 1995.p. 51-76.

. Formação de professores: para uma mudança educativa. Portugal: Porto Editora, 1999.

MAUÉS, O. C. Reformas internacionais da educação e formação de professores. Cadernos de Pesquisa. São Paulo, n. 118, p. 89-117, mar. 2003.

NÓVOA, A. Formação de professores e profissão docente. In: NÓVOA, A. (Org.). Os professores e a sua formação. 2. ed. Lisboa: Dom Quixote, 1995. p.15-33.

. Os professores e as histórias da sua vida. In: NÓVOA, A. (Org.). Vidas de professores. 2. ed. Porto: Porto Editora, 2000. p. 1130.

ROSSI, F.; HUNGER, D. O poder dos professores de Educação Física escolar na construção da formação continuada: uma análise à luz da teoria de Norbert Elias. Anais... I. Revista Educação: Teoria e Prática, v. 20, n. 36, 2010. p. 116-117.

TARDIF, M. Saberes docentes e formação profissional. Petrópolis: Vozes, 2002. 
Recebido em: 05/09/2011

Revisado em: 07/01/2012

Aprovado em: 18/03/2012

\section{Endereço para correspondência}

Dagmar Hunger

dag@fc.unesp.br

Universidade Estadual Paulista Júlio de Mesquita Filho

Faculdade de Ciências de Bauru, Departamento de Educação Física.

Av. Luiz Edmundo Carrijo Coube, $\mathrm{S} / \mathrm{N}$

Vargem Limpa

17000-000 - Bauru, SP - Brasil 